\title{
Use of Electrospinning to Develop Antimicrobial Biodegradable Multilayer Systems: Encapsulation of Cinnamaldehyde and Their Physicochemical Characterization
}

\author{
Miguel A. Cerqueira ${ }^{1,2}$ - María José Fabra ${ }^{3}$. Jinneth Lorena Castro-Mayorga ${ }^{3}$. \\ Ana I. Bourbon ${ }^{1} \cdot$ Lorenzo M. Pastrana $^{2}$ - António A. Vicente ${ }^{1}$. Jose M. Lagaron ${ }^{3}$
}

Received: 19 February 2016 / Accepted: 4 July 2016 / Published online: 15 July 2016

(C) Springer Science+Business Media New York 2016

\begin{abstract}
In this work, three active bio-based multilayer structures, using a polyhydroxybutyrate-co-valerate film with a valerate content of $8 \%$ (PHBV8) as support, were developed. To this end, a zein interlayer with or without cinnamaldehyde (CNMA) was directly electrospun onto one side of the PHBV8 film and the following systems were developed: (1) without an outer layer; (2) using a PHBV8 film as outer layer; and (3) using an alginate-based film as outer layer. These multilayer structures were characterized in terms of water vapour and oxygen permeabilities, transparency, intermolecular arrangement and thermal properties. The antimicrobial activity of the active bio-based multilayer systems and the release of CNMA in a food simulant were also evaluated. Results showed that the presence of different outer layers reduced the transport properties and transparency of the multilayer films. The active bio-based multilayer systems showed antibacterial activity against Listeria monocytogenes being the multilayer structure prepared with CNMA and PHBV outer layers (PHBV + zein/CNMA + PHBV) the one that showed the greater antibacterial activity. The release of CNMA depended on the multilayer structures, where both Fick's and
\end{abstract}

Miguel A. Cerqueira

miguelribeirocerqueira@gmail.com

María José Fabra

mjfabra@iata.csic.es

1 Centre of Biological Engineering, University of Minho, Campus de Gualtar, 4710-057 Braga, Portugal

2 INL-International Iberian Nanotechnology Laboratory, Av. Mestre José Veiga, 4715-330 Braga, Portugal

3 Novel Materials and Nanotechnology Group, IATA-CSIC, Av. Agustin Escardino 7, 46980 Paterna (Valencia), Spain
Case II transport - polymer relaxation explained the release of CNMA from the multilayer systems.

Overall, the deposition of electrospun CNMA-loaded zein fibres on a PHBV8 layer is a promising methodology for the development of active bio-based multilayer systems, with a great potential for food packaging applications.

Keywords Biodegradable polymers $\cdot$ Electro-hydrodynamic processing - Electrospinning Active packaging .

Multilayers $\cdot$ Polyhydroxyalkanoates

\section{Introduction}

Packaging materials based on bio-based and biodegradable materials have received great attention for the development of innovative packaging systems. Their biodegradability is considered to be a promising solution to environmental issues, but also their properties (e.g. solubility and transport properties) are considered unique when a controlled release of functional compounds is aimed at (Pinheiro et al. 2013; Souza et al. 2015). The development of active materials through the incorporation of antimicrobial and antioxidant compounds and their controlled release has attracted attention for several applications, such as active packaging and surface treatment of medical devices (Cerqueira et al. 2014; De Azeredo 2012; Kujawa et al. 2007; Tran et al. 2015).

Some of the drawbacks of bio-based and biodegradable active packaging materials are, according to the materials used, their hydrophilicity (i.e. polysaccharides and proteins), inadequate transport and thermal properties (i.e. polyhydroxyalkanoates PHAs and poly(3-hydroxybutyrate-PHB)) (Bordes et al. 2009; Cerqueira et al. 2010), the influence of added functional compounds in film's properties (e.g. transport and mechanical properties) and the decrease of the functional activity of the active compounds during processing. 
One of the most used approaches to improve film's performance is the use of blends (e.g. plasticizers) or the addition of nanomaterials (e.g. nanoclays) in order to achieve the desired properties (Bordes et al. 2009). However, these approaches do not solve completely the issues resulting from the incorporation of functional compounds. One of the alternatives is the use of biolayering technologies, where the development of multilayer systems (e.g. layer-by-layer and monolayer coating) can at the same time be used to enhance physicochemical properties and for the incorporation of functional compounds (Fabra et al. 2013a). This can be done through an electrohydrodynamic process (also called electrospinning), which will generate a coating or an interlayer with bio-adhesive properties (Fabra et al. 2013b; Fabra et al. 2015). In fact, one of the challenges in the development of multilayer bio-based and biodegradable films is to achieve adhesion between layers, e.g. between films from hydrophilic biopolymers (e.g. sodium alginate) and films from hydrophobic biopolyester layers (e.g. PHBV8). This technology also allows the entrapment of functional compounds within the electrospun material, which can be used as a carrier of the active compounds (Torres-Giner et al. 2010).

The electrospinning makes use of high-voltage electric fields to produce electrically charged jets from a polymer solution that can result in polymeric structured materials (e.g. fibre and particles) after drying. The conditions to obtain each of the structured materials are influenced by a great number of factors (e.g. polymer concentration, viscosity, solvent volatility, flow rate, voltage and humidity), and their modification can result in structures with different characteristics and properties. Additionally, this technology offers the possibility to develop active packaging multilayer structures producing simultaneously interlayers with encapsulation performance of the active compounds thus preserving their functional properties.

At this point, it is clear that one of the most interesting challenges for bio-based and biodegradable active packaging is to control their physicochemical properties and the release of functional compounds. This paper addresses these two challenges by using the electrospinning process. In particular, this work aims at evaluating the availability of the electrospinning process in order to develop antimicrobial multilayer packaging structures. To this end, a volatile compound, cinnamaldehyde (CNMA), was used as antimicrobial agent to develop electrospun active interlayers with bioadhesive properties. The active multilayer structures developed were characterized in terms of barrier, thermal, optical, antimicrobial activity and release kinetics in food simulants.

\section{Materials and Methods}

\section{Materials}

Sodium alginate (Algogel 3001) was provided by Cargill (France) and corn zein (grade Z3625, 22-24 kDa) and cinnamaldehyde (CNMA, purity $\geq 95 \%$ ) was purchased from Sigma-Aldrich (Madrid, Spain). Ethanol (96\% v/v purity) and glycerol were purchased from Panreac Quimica S.A. (Barcelona, Spain). All products were used as received without further purification. Polyhydroxybutyrate-co-valerate $8 \%$ (PHBV8; $100 \mu \mathrm{m}$ ) films were supplied by Goodfellow Cambridge Limited (Huntingdon, England).

\section{Preparation of Multilayer Films}

\section{Preparation of Electrospun Zein Interlayers Through Electrospinning}

Zein $(33 \%$, wt.) was prepared in an ethanolic solution $(80 \%$, $v / v)$ under magnetic stirring at room temperature. For the production of active zein solutions, the CNMA was added to the zein solution and stirred during more than $2 \mathrm{~h}$. A ratio of 1:0.75 of zein:CNMA was used.

To obtain the electrospun zein and zein/CNMA interlayers, the electrospinning solutions were transferred to $5-\mathrm{mL}$ plastic syringes and connected through PTFE tubes to a stainless steel needle $(\varnothing 0.9 \mathrm{~mm})$ and they were directly electrospun, using a voltage of $20 \mathrm{kV}$ and a flow rate of $0.15 \mathrm{~mL} / \mathrm{h}$, onto the inner layer of the PHBV8 film, using a cylindrical collector $(10 \mathrm{~cm}$ of diameter and $20 \mathrm{~cm}$ width) at $600 \mathrm{rpm}$ (rotating mandrel) during $7 \mathrm{~h}$ (in order to maximize the materials deposition). The distance between the needle and the plate was $10 \mathrm{~cm}$, and experiments were carried out at room temperature $\left(20^{\circ} \mathrm{C}\right)$ and $35 \% \mathrm{RH}$. The electrospinning apparatus was a Fluidnatek LE10 benchtop equipment, manufactured by Bioinicia S.L., Valencia (Spain).

\section{Production of Alginate Solutions and Films Made Thereof}

One gram of sodium alginate was suspended in $100 \mathrm{~mL}$ of distilled water, under magnetic stirring, during $12 \mathrm{~h}$ at $25^{\circ} \mathrm{C}$ followed by $2 \mathrm{~h}$ at $80{ }^{\circ} \mathrm{C}$ to guarantee that it was completely dissolved. Afterwards, $0.25 \mathrm{~g}$ of glycerol was added to the solution and stirred at room temperature during $2 \mathrm{~h}$. Alginate films were prepared by spreading $28 \mathrm{~mL}$ of the solution over the whole surface area of glass Petri dishes $($ diameter $=8.7 \mathrm{~cm})$, resting on a level surface. Films were dried during $24 \mathrm{~h}$ at $35^{\circ} \mathrm{C}$ and approximately $40 \%$ of RH. Dry films were peeled from the casting surface.

\section{Multilayer Assembly}

Once the zein ultrathin fibres were collected onto the PHBV8 films, three multilayer systems were evaluated: (1) without an outer layer (PHBV + zein); (2) covered with another PHBV8 film (sample code: PHBV + zein + PHBV); and (3) covered with an alginate-based film (sample code: $\mathrm{PHBV}+$ zein + alginate). When the zein ultrathin fibres included CNMA in 
their formulation, the systems were called (1) PHBV + zein/ CNMA; (2) PHBV + zein/CNMA + PHBV; and (3) PHBV + zein/CNMA + alginate. The resulting multilayer system was annealed in a hot press (Carver 4122 , USA) at $130{ }^{\circ} \mathrm{C}$ during $2 \mathrm{~min}$. Before testing, multilayer systems were maintained in desiccators at $25^{\circ} \mathrm{C}$ and $0 \% \mathrm{RH}$ using dry silica gel (Panreac Quimica S.A., Barcelona, Spain).

\section{Scanning Electron Microscopy}

A Hitachi S-4800 (Hitachi High Technology Corp., Tokyo, Japan) was used to observe the morphology of films crosssections and surface. Cross-sections of the multilayer films were prepared by cryo-fracture of the films using liquid $\mathrm{N}_{2}$. The samples were mounted on bevel sample holders with double-sided adhesive tape and sputtered with $\mathrm{Au} / \mathrm{Pd}$ under vacuum. Samples were observed using an accelerating voltage of $10 \mathrm{kV}$.

\section{Optical Properties}

The transparency of the developed multilayer structures was determined through the surface reflectance spectra in a spectrocolorimeter CM-3600d (Minolta Co., Tokyo, Japan) with a $10 \mathrm{~mm}$ illuminated sample area. The internal transmittance $\left(\mathrm{T}_{\mathrm{i}}\right)$ of the samples was determined by applying the Kubelka-Munk theory (Hutchings 1999) for multiple scattering to the reflection spectra, following the methodology described elsewhere (Fabra et al. 2014). Measurements were taken in triplicate for each multilayer film by using both a white and black background.

\section{Water Vapour Permeability}

The water vapour permeability (WVP) of multilayer films was determined according to ASTM-E96-15 (ASTM-E96-15 2011) gravimetric method using Payne permeability cups (Elcometer SPRL, Hermelle/s Argenteau, Belgium) of $3.5 \mathrm{~cm}$ diameter. For each type of multilayer film, measurements were replicated three times and water vapour permeability was carried out at $25^{\circ} \mathrm{C}$ and $0-100 \%$ relative humidity gradient, which was generated by using dry silica gel and distilled water, respectively. The cups were weighed periodically $(0.0001 \mathrm{~g})$ after the steady state was reached. Cups with aluminium films were used as control samples to estimate solvent loss through the sealing. Water vapour permeation rate was calculated from the steady-state permeation slopes (7 points) obtained from the regression analysis of weight loss data vs. time, and weight loss was calculated as the total cell loss minus the loss through the sealing. Permeability was obtained by multiplying the permeance by the average film thickness. Films thickness was measured at least five different points using a digital micrometer (Mitutoyo, Spain) with $\pm 0.001 \mathrm{~mm}$ accuracy.

\section{Oxygen Permeability}

The oxygen permeability coefficient was derived from the oxygen transmission rate (OTR) measurements recorded, in duplicate, using an Oxygen Permeation Analyzer M8001 (Systech Illinois, UK) at $80 \% \mathrm{RH}$ and $23{ }^{\circ} \mathrm{C}$. A sample of each multilayer film $\left(5 \mathrm{~cm}^{2}\right)$ was placed in the test cell and pneumatically clamped in place. The samples were previously purged with nitrogen in the humidity equilibrated samples, before exposure to an oxygen flow of $10 \mathrm{~mL} / \mathrm{min}$. In order to obtain the oxygen permeability, film thickness was considered in each case.

\section{Thermal Analysis}

Thermal analysis of materials was carried out on a DSC analyzer (Perkin Elmer, Inc., DSC 8000, USA). Approximately $3 \mathrm{mg}$ of sample was placed into aluminium pans (PerkinElmer, DSC, BO14), sealed and heated between 20 and $200{ }^{\circ} \mathrm{C}$ at a scanning speed of $10{ }^{\circ} \mathrm{C} / \mathrm{min}$ in a nitrogen atmosphere using a refrigerating cooling accessory (Intracooler 2, Perkin-Elmer, USA). An empty aluminium pan was used as reference. The melting endotherm and the controlled crystallization at $10{ }^{\circ} \mathrm{C} / \mathrm{min}$ were analysed. Calibration was performed using an indium sample.

The crystallinity degree $(X)$ was estimated from the corrected enthalpy for total PHBV content in the samples, using the ratio between the enthalpy of the studied material and the enthalpy of a perfect PHBV crystal as presented in Eq. 1:

$X(\%)=\frac{\Delta H_{m}}{\Delta H_{m}^{0}} 100$

where $\Delta H_{m}^{0}$ is the melting enthalpy of an infinity PHBV crystal (109 J/g) (Scandola et al., 1997). The tests were done in duplicate.

\section{Fourier Transform Infrared Spectroscopy}

Fourier transform infrared (FTIR) spectra of the films were recorded with FTIR Tensor 37 equipment (Bruker, Germany) in the wavelength range $4000-600 \mathrm{~cm}^{-1}$ at a resolution of $4 \mathrm{~cm}^{-1}$, using attenuated total reflection mode (ATR). The absorbance of each FTIR spectrum was normalized between 0 and 1 . The measurements were performed in triplicate. 


\section{Antimicrobial Analysis}

To evaluate the antimicrobial performance of the obtained films, a modification of the JIS Z 2801 was used (Japanese Industrial Standard, JIS Z 2801, 2010). Briefly, a bacterial suspension of Listeria monocytogenes as microorganism indicator containing about $5 \times 10^{5} \mathrm{CFU} / \mathrm{mL}$ was applied onto the test multilayer films of $2 \times 2 \mathrm{~cm}$ and covered by an inert piece of low-density polyethylene (LDPE) of $1.5 \times 1.5 \mathrm{~cm}$ and $10 \mu \mathrm{m}$ thickness. After incubation at $24{ }^{\circ} \mathrm{C}$ and a relative humidity of at least $95 \%$ for $24 \mathrm{~h}$, bacteria were recovered with PBS, 10 -fold serially diluted and incubated at $37^{\circ} \mathrm{C}$ for $24 \mathrm{~h}$ in order to quantify the number of viable bacteria by conventional plate count. PHVB8 films (without CNMA) were used as a negative control. The antimicrobial activity was evaluated as synthesized ( 0 days) and after 1 month ageing. The reduction $(R)$ of $L$. monocytogenes was calculated by determining $\left(N_{0}-N_{t}\right) / N_{0}$, where $N_{0}$ is the average of the number of viable bacteria on the untreated test piece after $24 \mathrm{~h}$ and $N_{t}$ is average of the number of viable bacteria on the antimicrobial test piece after $24 \mathrm{~h}$. Three replicate experiments were performed for each sample.

\section{Release Analysis}

The produced multilayer films were cut in $4 \mathrm{~cm}^{2}$ samples. The squares obtained from the three multilayer structures were immersed into $50 \mathrm{~mL}$ of an ethanolic solution $(10 \%, v / v)$ at $25^{\circ} \mathrm{C}$ that was used as food simulant (for foods that have a hydrophilic character and are able to extract hydrophilic substances) (Regulation 2011), under moderate stirring (300 rpm). Release kinetics was evaluated by monitoring the concentration of the CNMA in the surrounding solution until an equilibrium value was reached. The concentration of CNMA was assessed by measuring the absorbance (Elisa Biotech Synergy HT, USA) at $330 \mathrm{~nm}$ using a calibration curve of absorbance (nm) versus concentration of free CNMA $\left(\mathrm{mg} \mathrm{mL}^{-1}\right)\left(y=8.3477 x+0.0035, R^{2}=0.999\right)$. For each experimental condition, at least three true replicates were conducted.

Release kinetics: The release profile of CNMA from the multilayer systems was evaluated using Berens and Hofenberg model (Berens and Hopfenberg 1978) that considers the contribution from both Fickian diffusion and polymeric relaxations of the matrix:

$M_{t}=M_{t, F}+M_{t, R}$

where $M_{t, F}$ are the contributions of Fickian diffusion and $M_{t, R}$ the contributions of polymeric relaxations.

The mass transport related to Brownian motion in a thin slab of polymer when immersed in a sufficiently large amount of water can be described by the Fick's second law for a plane sheet with constant boundary conditions (Crank 1975). For polymer relaxation, it is driven by the swelling ability of the polymer and is related to the dissipation of stress induced by the entry of the penetrant and can be described as a distribution of relaxation times, each following a kinetic of first order (Berens and Hopfenberg 1978). Thus, the release of compounds from a hydrophilic polymer slab can be described by:

$$
\begin{aligned}
M_{t}= & M_{\infty, F}\left[1-\frac{8}{\pi^{2}} \sum_{n=0}^{\infty} \frac{1}{(2 n+1)^{2}} \exp \left[(-2 n+1)^{2} K_{F} t\right]\right] \\
& +\sum_{i} M_{\infty, R i}\left[1-\exp \left(-K_{R i} t\right)\right]
\end{aligned}
$$

where $K_{F}$ and $K_{R}$ are Fickian diffusion and relaxation rate constants, respectively.

The model of Eq. 3 can then be used to describe pure Fickian $\left(M_{l, F} \neq 0\right.$ and $\left.i=0\right)$; anomalous $\left(M_{l, F}\right.$ and $\left.\mathrm{i} \neq 0\right)$ or Case II $\left(M_{l, F}=0\right.$ and $\left.\mathrm{i} \neq 0\right)$ transport. Experimental results were analysed by fitting Eq. 3 (LSM) in order to assess the mechanisms involved in CNMA release from the multilayer systems.

\section{Statistical Analysis}

Statistical analysis was performed using one-way ANOVA with a $95 \%$ confidence level using Vassarstats (http://vassarstats.net). The non-linear estimation module of Statistica ${ }^{\circledR 7}$ (Statsoft, Tulsa, Ok, USA) was used to fit Eq.3 to experimental data. The adjusted determination coefficient $\left(R^{2}\right)$ and the square root mean square error (RMSE) which corresponds to the square root of the sum of the squared residues (SSE) divided by the regression degrees of freedom were calculated and residuals inspection for randomness, and normality was performed in order to determine regressions quality. Standardised Halved Width (SHW\%) was assessed to determine the precision of the estimated parameters.

\section{Results and Discussion}

\section{Morphology}

The incorporation of active compounds and new materials in a biopolymer-based matrix can be difficult considering the physicochemical properties of the active compounds (e.g. solubility and hydrophobicity) and the biopolymer used (e.g. type of structure, molecular weight and polarity). In addition, when the aim is to add active compounds to packaging materials (being needed high processing temperatures), it is fundamental to understand how the active compounds will behave and maintain their functional properties. In this work, preliminary studies were performed evaluating different temperatures 
of annealing for the assembly of multilayer systems; the objectives were to guarantee a good adhesion between layers and the least exposure of CNMA to high temperatures. Figure 1 shows the overall appearance of the developed active multilayer films. Multilayer films, when compared with PHBV8, showed a higher opacity (decrease of internal transmittance- $T i$ values) being PHBV + zein/CNMA + PHBV film the one with the higher heterogeneous aspect which is in agreement with the results obtained for $T i$ (Fig. 3).

Furthermore, scanning electron microscopy (SEM) was used to evaluate the morphology of the multilayer films (i.e. arrangement of the multilayer film) and the electrospun zein fibres when deposited onto PHBV8 films. Figure 2a shows a SEM image of the electrospun zein/CNMA interlayer before the annealing process on the surface of PHBV8-multilayer without outer layer, where the formation of zein fibres at sub-micro scale is visible (width $<1 \mu \mathrm{m}$ ). Figure $2 \mathrm{~b}$ shows the cross-section from the PHBV8-multilayer with alginate as outer layer where it is possible to observe a layered structure where the zein interlayers present a thickness of approximately $3 \mu \mathrm{m}$, showing a good adhesion between PHBV8 and alginate layers.

Both visual and microscopy observation showed that the development of the three multilayers systems is possible with an annealing process at $130{ }^{\circ} \mathrm{C}$ during $2 \mathrm{~min}$. This was the lower temperature and time of annealing that allow the formation of multilayer systems with these materials and it is in agreement with published works using biopolymers (Fabra et al. 2014; Fabra et al. 2015). The thickness values of the multilayer films were also measured and are presented in Table 1. As expected, the presence of the layers led to thick films achieving the higher value for the PHBV + zein/ CNMA + alginate multilayer films.

\section{Optical Properties}

Optical properties provide important information on the influence that the incorporation of active compounds in packaging materials has in their appearance and transparency; they can be related with the surface and internal structure of the material. The transparency of the multilayer films was evaluated by means of the internal transmittance $\left(T_{i}\right)$. Figure 3 shows the spectral curves of $T_{i}$ of the developed multilayers and of the neat alginate and PHBV8 layers. Over the wavelength considered, a similar pattern was observed for all the tested films although the degree of transparency was greatly affected by the composition of the multilayer structure. High $T_{i}$ values correspond to a more transparent film, indicating a more homogeneous refractive index through their structure. The first observation to highlight is that the neat alginate and PHBV8 layers showed the higher $T_{i}$ values, being the alginate a little more transparent. However, the addition of the zein and zein/CNMA interlayer greatly decreased the $T_{i}$ values of the
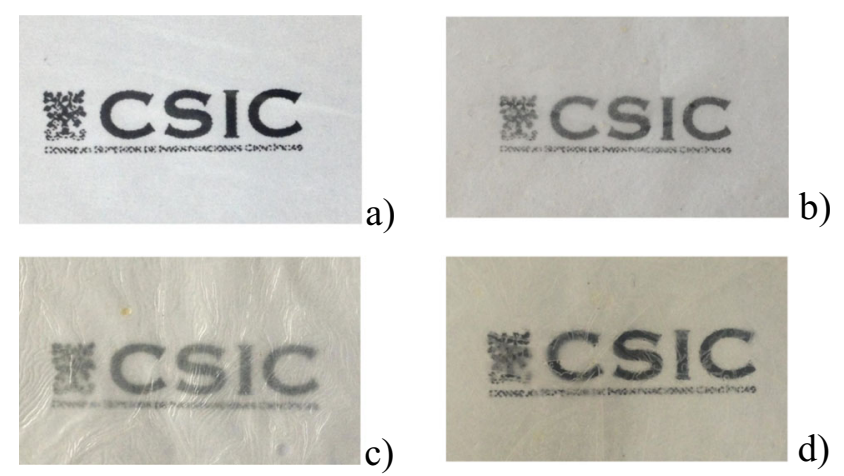

Fig. 1 Images of the film and multilayers. a PHBV8; b PHBV + zein/ CNMA; $\mathbf{c} \mathrm{PHBV}+$ zein/CNMA + PHBV; d PHBV8 + zein/CNMA + alginate

developed multilayer systems, indicating that these multilayer structures became less transparent. This behaviour can be related with the increase of the tortuosity of the internal structure which affected the light transmission/dispersion behaviour of the multilayer systems. It is worthwhile noting that the multilayer films prepared with alginate as outer layer showed higher $T_{i}$ values than their counterparts prepared with PHBV8, in agreement with the higher transparency observed for the neat alginate. The presence of CNMA in multilayers (excluding the multilayers with alginate) also leads to a decrease of $T_{i}$ values showing that the incorporation of CNMA in the multilayers change their transparency and thus their internal structure probably due to the presence of CNMA with different refractive index. In fact, the transparency of the multilayer films was greatly reduced for those prepared with electrospun zein or zein/CNMA interlayer and PHBV8 as outer layers.

\section{Water Vapour and Oxygen Permeabilities}

Table 1 presents water vapour (WVP) and oxygen $\left(\mathrm{O}_{2} \mathrm{P}\right)$ permeability values of the neat alginate and PHBV8 films as well as the developed multilayers structures. As expected, neat PHBV8 films showed lower WVP permeability values than the neat alginate films which can be easily explained by the hydrophilic character of the alginate. It is well known that the permeability to water vapour is highly related to the hydrophobicity of the materials used for the development of multilayers (Cerqueira et al. 2012) but also to the layer which is in contact with the $100 \%$ of RH during the WVP assays (Fabra et al. 2014). This influence was clear when alginate was used as outer layer; leading to an increase of the WVP values. Nevertheless, multilayer structures using alginate as outer layer showed good barrier properties to oxygen presenting the lowest values of $\mathrm{O}_{2} \mathrm{P}(\mathrm{PHBV}+$ zein + alginate and $\mathrm{PHBV}+$ zein/CNMA + alginate).

It is important to highlight that multilayer systems present higher WVP values than PHBV8 films, showing that the 
Fig. 2 SEM images of a of the electrospun zein nanofibres on PHBV and $\mathbf{b}$ cross-section of the $\mathrm{PHBV}+$ zein + alginate system

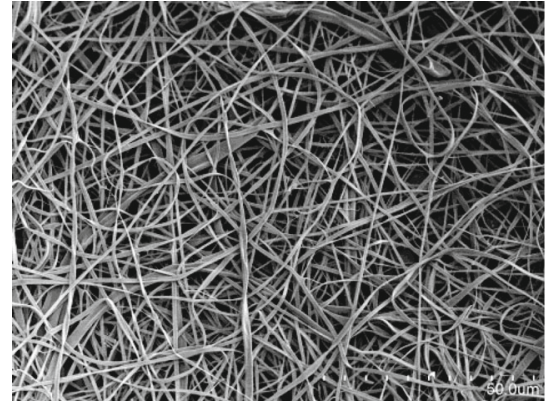

a)

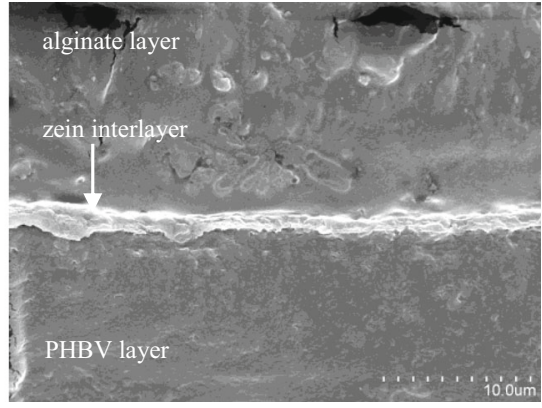

b) interlayer of electrospun zein and the annealing process changes the film structure increasing the WVP and $\mathrm{O}_{2} \mathrm{P}$ values (except to $\mathrm{O}_{2} \mathrm{P}$ of $\mathrm{PHBV}+$ zein + alginate and PHBV + zein/ CNMA + alginate films). A similar behaviour was previously observed in polylactic acid (PLA)-zein multilayer systems where water vapour barrier properties decreased over $10 \%$ as compared to control PLA films (without zein interlayer) (Busolo et al. 2009). They attributed these differences to the greater hydrophilic nature of PLA which did not protect zein interlayer from plasticization and swelling as did the PHB material (Fabra et al. 2013b). In the present work, the low barrier properties of PHBV8 multilayer films could be ascribed to the higher WVP values of this material as compared to the neat PHB which did not afford the inner layer from swelling. In fact, it is well known that PHB materials exhibit lower water permeability values when compared to PHBV and that the water vapour barrier decreases with increasing $\mathrm{HV}$ content (Plackett and Siro 2011). Therefore, it can be concluded that the nature of the outer layer can play a crucial role in water vapour barrier properties of the multilayer structure.

The incorporation of CNMA leads to a decrease of the WVP and $\mathrm{O}_{2} \mathrm{P}$ values when compared with multilayer films without CNMA (except to WVP and $\mathrm{O}_{2} \mathrm{P}$ of $\mathrm{PHBV}+$ zein + alginate and $\mathrm{PHBV}+$ zein/CNMA + alginate films and $\mathrm{O}_{2} \mathrm{P}$ of $\mathrm{PHBV}+$ zein + PHBV and $\mathrm{PHBV}+$ zein/CNMA + PHBV films). This behaviour can be related with the hydrophobic character of CNMA and their effect in the structure and thus in their transport properties. Comparing to previous works, the obtained WVP and $\mathrm{O}_{2} \mathrm{P}$ values for the multilayer films ranged between those obtained for other multilayer systems and films (Fabra et al. 2014; Fabra et al. 2013b).

\section{Fourier Transform Infrared Spectroscopy Characterization}

ATR-FTIR spectra were recorded from the various multilayer films being evaluated the each side. Figure 4 shows the ATRFTIR spectra of the developed multilayers with and without the presence of CNMA (grey and black lines, respectively). For multilayers with PHBV and alginate as outer layers, the presence of CNMA was not detected indicating that during the multilayer production, the CNMA was maintained in the inner layer of electrospun zein. Figure $4 a$, b shows the ATR-FTIR spectra of $\mathrm{PHBV}+$ zein and/or PHBV + zein/CNMA for the PHBV and zein side, respectively, where the presence of a new peak due the CNMA presence is detectable at $1670 \mathrm{~cm}^{-1}$ in
Table 1 Values of water vapour (WVP) and oxygen $\left(\mathrm{O}_{2} \mathrm{P}\right)$ permeabilities of the multilayers and of the films used for their production

\begin{tabular}{llll}
\hline Sample & $\begin{array}{l}\text { WVP } \times 10^{15} \mathrm{~kg} \\
(\mathrm{~m} \mathrm{~Pa} \mathrm{~s})^{-1}\end{array}$ & $\begin{array}{l}\mathrm{O}_{2} \mathrm{P} \times 10^{17} \mathrm{~m}^{3} \mathrm{~m} \\
\left(\mathrm{~m}^{2} \mathrm{~s} \mathrm{~Pa}\right)^{-1}\end{array}$ & Thickness (mm) \\
\hline PHBV & $3.53^{\mathrm{a}}$ & $0.290 \pm 0.006 \mathrm{a}$ & $0.011 \pm 0.00 \mathrm{a}$ \\
Alginate & $276.77^{\mathrm{a}}$ & $0.385 \pm 0.047 \mathrm{a}$ & $0.053 \pm 0.005 \mathrm{~b}$ \\
PHBV-zein & $41.92 \pm 7.44 \mathrm{a}$ & $327.01 \pm 24.89 \mathrm{~b}$ & $0.045 \pm 0.015 \mathrm{~b}$ \\
PHBV-zein/CNMA & $7.91 \pm 0.53 \mathrm{~b}$ & $19.75 \pm 5.94 \mathrm{c}$ & $0.018 \pm 0.003 \mathrm{c}$ \\
PHBV-zein-PHBV & $17.78 \pm 2.62 \mathrm{c}$ & $3.603 \pm 0.095 \mathrm{c}$ & $0.053 \pm 0.017 \mathrm{~b}$ \\
PHBV-zein/CNMA-PHBV & $9.80 \pm 1.08 \mathrm{~b}$ & $33.79 \pm 23.94 \mathrm{c}$ & $0.037 \pm 0.006 \mathrm{~b}$ \\
PHBV-zein-alginate & $75.64 \pm 6.13 \mathrm{~d}$ & $0.119 \pm 0.016 \mathrm{~d}$ & $0.055 \pm 0.005 \mathrm{~b}$ \\
PHBV-zein/CNMA- & $67.48 \pm 11.71 \mathrm{~d}$ & $0.106 \pm 0.07 \mathrm{~d}$ & $0.069 \pm 0.011 \mathrm{~d}$ \\
$\quad$ & & & \\
\hline
\end{tabular}

Values reported are the means \pm standard deviations

Different letters $(\mathrm{a}-\mathrm{d})$ in the same column indicate a statistically significant difference $(p<0.05)$

${ }^{\text {a }}$ Only one measurement was performed 
Fig. 3 Spectral distribution of internal transmittance $\left(T_{i}\right)$ of the neat PHBV8 and alginate films and of the multilayer structures

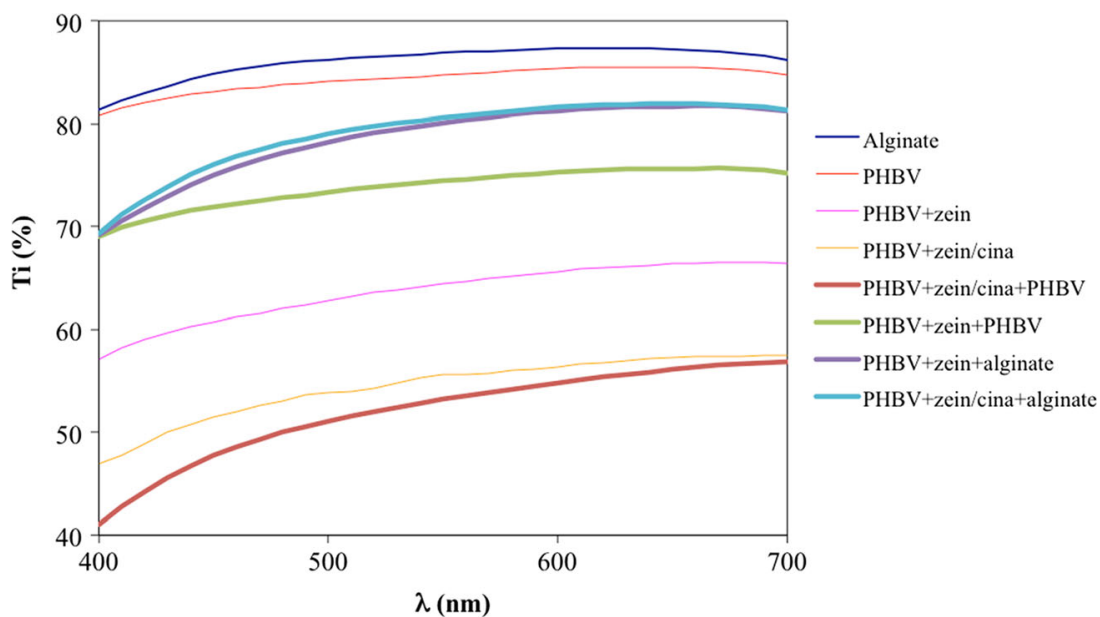

the spectra of zein side. This peak is explained by the carbonyl stretching of the aldehyde group. For the PHBV side, a shoulder near to $1670 \mathrm{~cm}^{-1}$ was observed that increases when the zein side was analysed, indicating that CNMA was entrapped into the electrospun fibres.

For the FTIR spectra of PHBV + zein/CNMA + PHBV (Fig. 4c, d) and PHBV + zein/CNMA + alginate (Fig. 4e, f) multilayer structures, this behaviour was not observed, being the spectra similar to the ones of the multilayer without
CNMA, confirming the successful development of the multilayer system and the presence of the CNMA in the inner layer.

\section{Thermal Analysis}

Table 2 displays the values of melting and crystallization enthalpy values $\left(\Delta \mathrm{H}_{\mathrm{m}}\right.$ and $\Delta \mathrm{H}_{\mathrm{c}}$, respectively) and melting $\left(\mathrm{T}_{\mathrm{m}}\right)$ and crystallization $\left(\mathrm{T}_{\mathrm{c}}\right)$ temperatures of the multilayer structures. According to the type of multilayer, different behaviours
Fig. 4 ATR-FTIR spectra of a PHBV + zein multilayer from the PHBV side, b PHBV + zein multilayer from the zein side, $\mathbf{c}$ $\mathrm{PHBV}+$ zein + PHBV multilayer from the PHBV side, d PHBV + zein + PHBV multilayer from the PHBV side, e PHBV + zein + alginate multilayer from the PHBV side and $\mathbf{f} \mathrm{PHBV}+$ zein + alginate multilayer from the alginate side. Black lines are the multilayers spectra with cinnamaldehyde and grey lines are the multilayers spectra without cinnamaldehyde

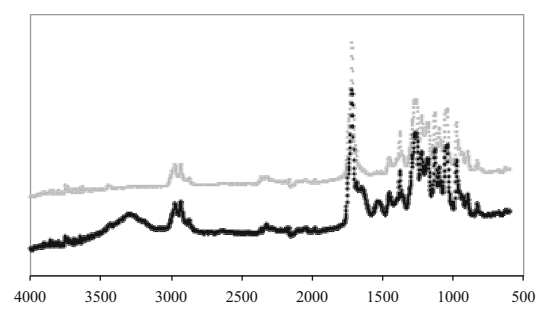

(a)
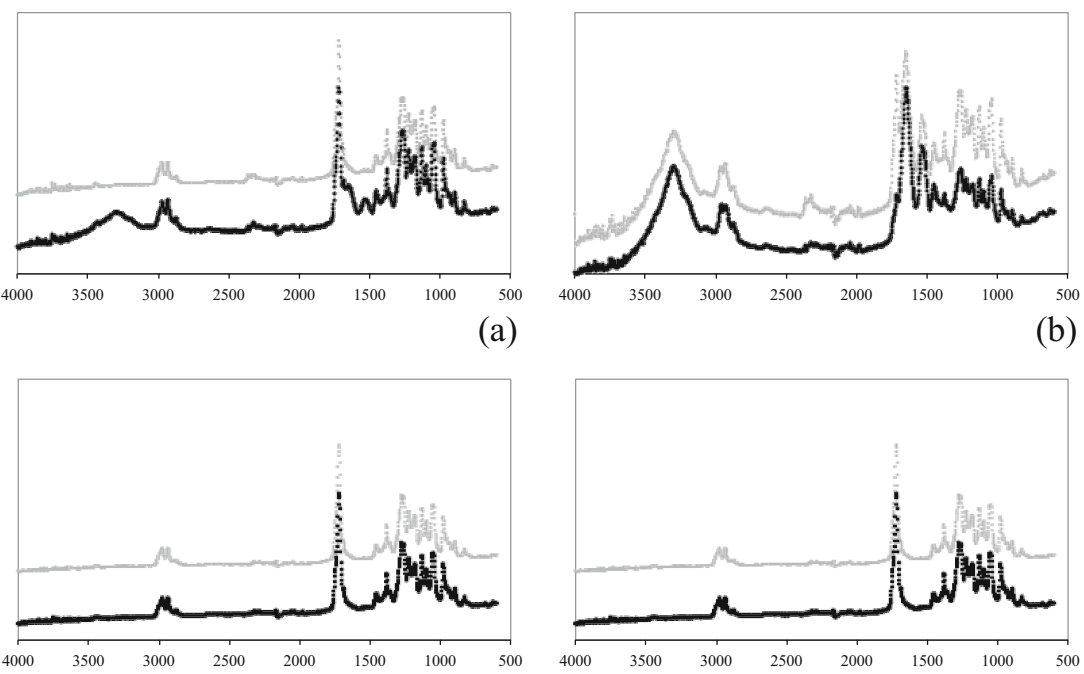

(c)

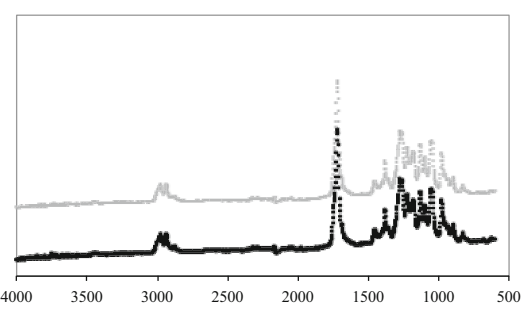

(d)
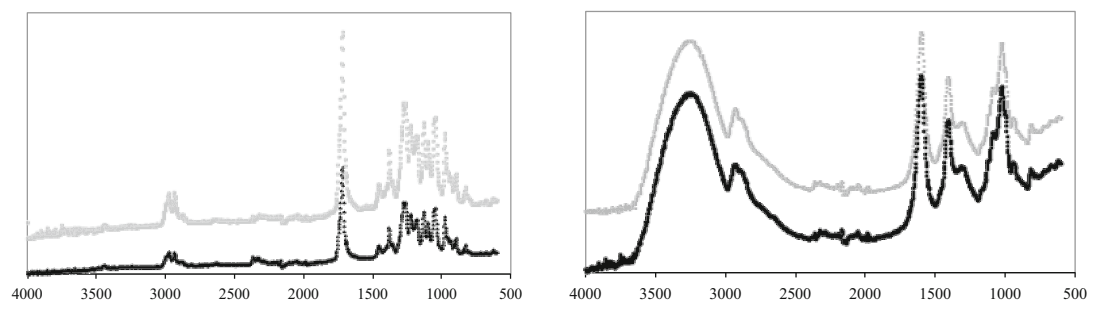

(e) 
Table 2 Thermal parameters of multilayer films

\begin{tabular}{lllllll}
\hline Sample & $\mathrm{T}_{\mathrm{m} 1}\left({ }^{\circ} \mathrm{C}\right)$ & $\mathrm{T}_{\mathrm{m} 2}\left({ }^{\circ} \mathrm{C}\right)$ & $\Delta \mathrm{H}_{\mathrm{m} 1}(\mathrm{~J} / \mathrm{g}$ PHBV8) & $\mathrm{T}_{\mathrm{c}}\left({ }^{\circ} \mathrm{C}\right)$ & $\Delta \mathrm{H}_{\mathrm{c}}(\mathrm{J} / \mathrm{g}$ PHBV8) & $X(\%)$ \\
\hline PHBV + zein + PHBV & $145.2 \pm 2.6 \mathrm{a}$ & $156.7 \pm 2.7 \mathrm{a}$ & $60.0 \pm 6.1 \mathrm{a}$ & $101.4 \pm 2.7 \mathrm{a}, \mathrm{b}$ & $-54.3 \pm 0.9 \mathrm{a}$ & $55.1 \pm 5.6 \mathrm{a}$ \\
PHBV + zein/CNMA + PHBV & $143.5 \pm 1.53 \mathrm{a}$ & $154.9 \pm 1.4 \mathrm{a}$ & $50.6 \pm 2.0 \mathrm{a}$ & $98.7 \pm 2.3 \mathrm{a}, \mathrm{b}$ & $-51.8 \pm 4.8 \mathrm{a}$ & $50.2 \pm 14.9 \mathrm{a}$ \\
PHBV + zein + alginate & $148.1 \pm 2.19 \mathrm{a}$ & - & $54.7 \pm 16.3 \mathrm{a}, \mathrm{c}$ & $82.8 \pm 6.3 \mathrm{a}$ & $-35.1 \pm 13.9 \mathrm{a}, \mathrm{b}$ & $46.4 \pm 1.8 \mathrm{a}$ \\
PHBV + zein/CNMA + alginate & $150.9 \pm 4.63 \mathrm{a}$ & - & $21.2 \pm 1.5 \mathrm{~b}$ & $92.0 \pm 1.5 \mathrm{a}, \mathrm{b}$ & $-4.3 \pm 3.2 \mathrm{~b}$ & $19.5 \pm 1.4 \mathrm{~b}$ \\
PHBV + zein & $144.4 \pm 0.5 \mathrm{a}$ & $156.5 \pm 0.6 \mathrm{a}$ & $55.0 \pm 3.1 \mathrm{a}$ & $101.7 \pm 0.8 \mathrm{~b}$ & $-49.7 \pm 2.6 \mathrm{a}$ & $50.4 \pm 2.8 \mathrm{a}$ \\
PHBV + zein/CNMA & $144.2 \pm 4.0 \mathrm{a}$ & $154.6 \pm 3.4 \mathrm{a}$ & $41.9 \pm 0.4 \mathrm{c}$ & $99.81 \pm 3.2 \mathrm{a}, \mathrm{b}$ & $-47.2 \pm 0.8 \mathrm{a}$ & $38.5 \pm 0.4 \mathrm{c}$ \\
\hline
\end{tabular}

Values reported are the means \pm standard deviations. Different letters $(\mathrm{a}-\mathrm{c})$ in the same column indicate a statistically significant difference $(p<0.05)$ $T_{m}$ temperature of melting, $\Delta H_{m}$ enthalpy of melting, $T_{m}$ temperature of crystallization, $\Delta H_{m}$ enthalpy of crystallization, $X$ crystallinity degree

were observed regarding the amount of PHBV and alginate present in the sample used and the presence of CNMA. The multilayers composed by two layers of PHBV present a typical melting temperature for PHB and their blends (Jost and Langowski 2015). Two peaks are observed around 144 and $155^{\circ} \mathrm{C}$. The presence of an alginate outer layer leads to the appearance of only one peak of melting and the presence of CNMA leads to a decrease of the $\Delta \mathrm{H}_{\mathrm{m}}$ and thus a decrease of the crystallinity values of the multilayers films; i.e. the incorporation of CNMA will leads to a change in PHBV structure and therefore in the crystallinity degree.

\section{Antimicrobial Study}

Figure 5 displays the antimicrobial activity of the developed bilayer PHBV + zein/CNMA and multilayer PHBV + zein/ $\mathrm{CNMA}+\mathrm{PHBV}$ and PHBV + zein/CNMA + alginate films.
The antimicrobial test showed that bilayer films prepared with PHBV-electrospun active layer presents very low antimicrobial activity with a reduction in Listeria monocytogenes levels less than $1 \log \mathrm{CFU} / \mathrm{mL}(0.71 \log \mathrm{CFU} / \mathrm{mL})$ after $24 \mathrm{~h}$ of exposure. Similar behaviour was observed after one month of storage at $0 \% \mathrm{RH}$ and $24{ }^{\circ} \mathrm{C}$ with only a reduction of $0.81 \mathrm{log}$ $\mathrm{CFU} / \mathrm{mL}$. In contrast, the antimicrobial activity of the multilayer films prepared with $\mathrm{PHBV}+$ zein/CNMA + PHBV or $\mathrm{PHBV}+$ zein/CNMA + alginate was higher than that obtained for the bilayer PHBV + zein/CNMA film. On one hand, the freshly made multilayer PHBV + zein/CNMA + PHBV films showed a significantly and markedly greater antibacterial activity, with a decrease in the viable cell number of more than $5.24 \log \mathrm{CFU} / \mathrm{mL}$ as compared to the control film (without the active compound). However, the antimicrobial activity of $\mathrm{PHBV}+\mathrm{zein} / \mathrm{CNMA}+\mathrm{PHBV}$ multilayer system was progressively reduced by up $2.18 \log \mathrm{CFU} / \mathrm{mL}$ after 30 days of
Fig. 5 Antimicrobial activity of films against Listeria monocytogenes after $24 \mathrm{~h}$ of exposure. The dashed line depicts the initial inoculum. Mean values with different letters represent significant differences $(p<0.05)$ among the samples as determined with a one-way analysis of variance (ANOVA) and Tukey's multiple comparison tests. The detection limit was $20 \mathrm{CFU} / \mathrm{mL}$

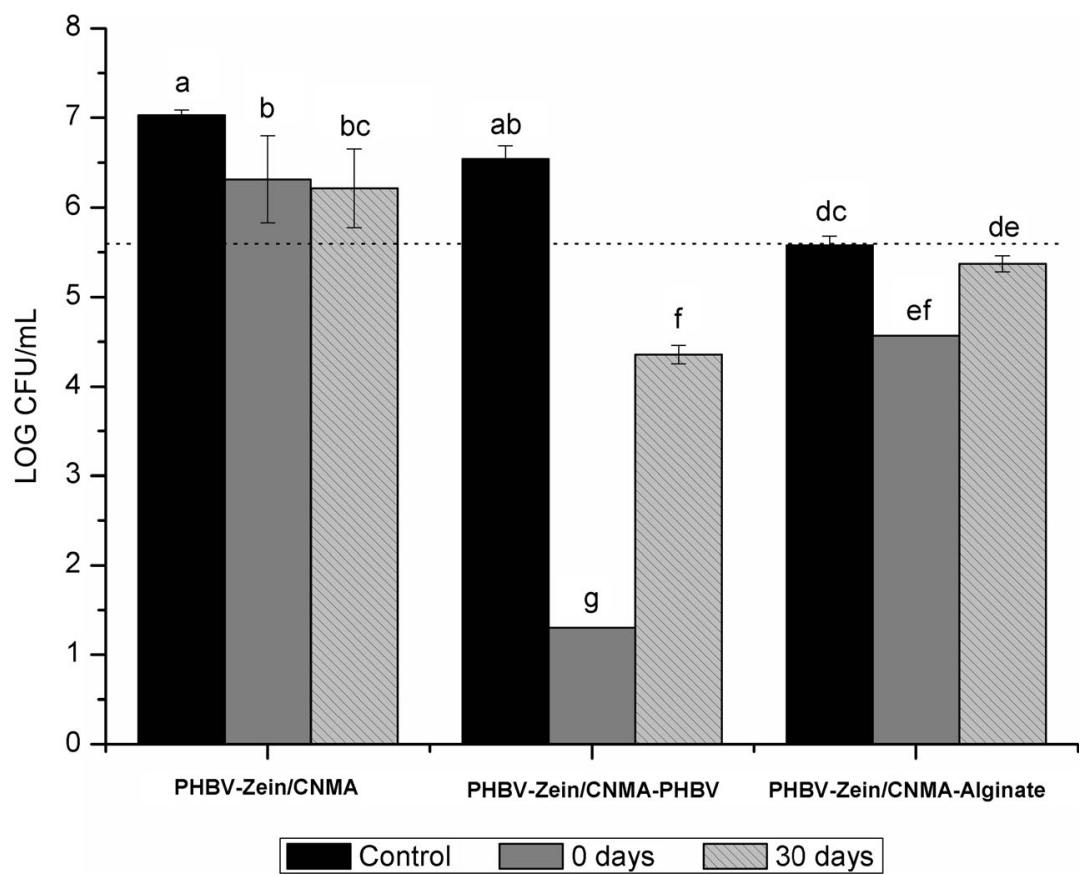


Fig. 6 CNMA release experimental data from a $\mathrm{PHBV}+$ zein/CNMA; b $\mathrm{PHBV}+$ zein/CNMA + PHBV; and $\mathbf{c} \mathrm{PHBV}+$ zein/CNMA + alginate. d Example of fitting of Eq. 2 to CNMA release experimental data from $\mathrm{PHBV}+$ zein/cina system ((grey dots) experimental results and (black lines) model-generated values)
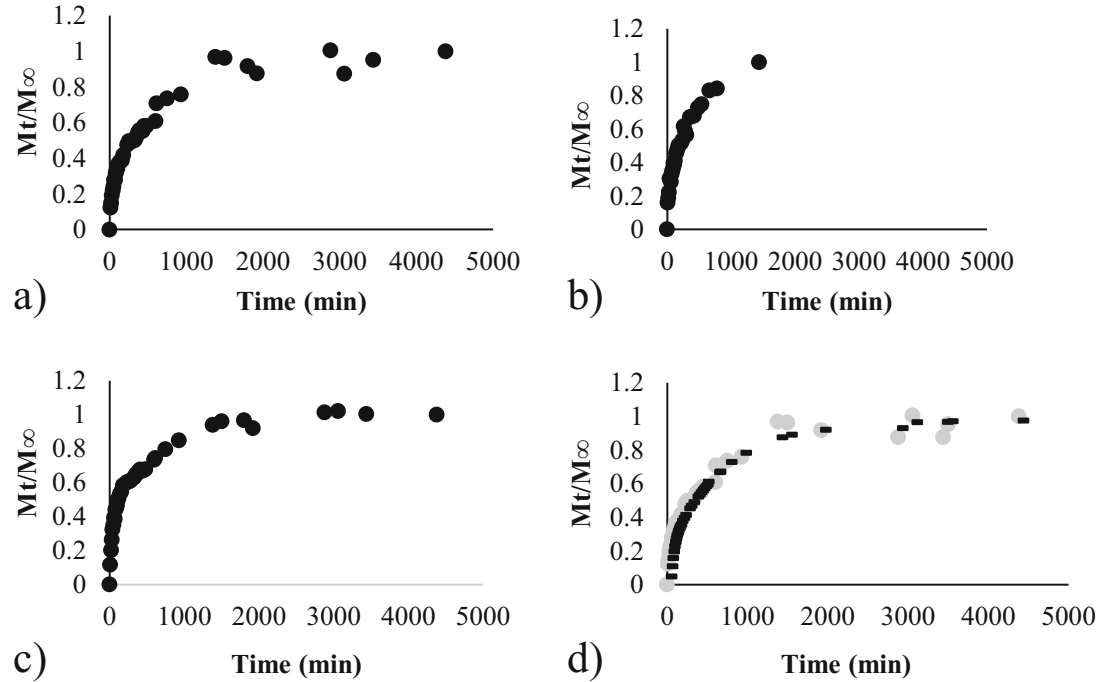

storage at $0 \% \mathrm{RH}$ and $24{ }^{\circ} \mathrm{C}$. Even so, the antimicrobial activity of the CNMA was greater when the electrospun active layer was used as an inner layer in a multilayer film, given that the outer layer protected the evaporation of the volatile compound during both film formation (annealing) and storage. These results proved the potential use of the multilayer systems to maintain active the CNMA in the packaging material.

On the other hand, multilayer films prepared with $\mathrm{PHBV}+$ zein/CNMA + alginate showed a less marked antimicrobial activity than their counterparts prepared with $\mathrm{PHBV}+\mathrm{zein} /$ CNMA + PHBV films, showing a reduction of 1.01 and 0.2 $\log \mathrm{CFU} / \mathrm{mL}$ for freshly made and stored alginate multilayer structures, respectively. These differences can be attributed to the fact that alginate is a hydrophilic matrix which absorbed water and induced changes in the film structures. Therefore, the antimicrobial compound could be partially released before the antimicrobial test and it was able to evaporate or diffuse to the environment. The antibacterial activity is in agreement to that reported in previous works. For instance, gliadin films incorporating $5 \%$ CNMA were highly effective against fungal growth of $P$. expansum and $A$. niger both in vitro and in real food systems after 45 days of storage at $20{ }^{\circ} \mathrm{C}$ and $0 \% \mathrm{RH}$ (Balaguer et al. 2013). Also, the bacteriostatic effect of polyethylene-co-vinylacetate (EVA) films containing $7 \%$ of CNMA was reported by Nostro et al. (Nostro et al. 2012) where a reduction of about $1 \log$ CFU of L. monocytogenes was observed. Furthermore, to the best of our knowledge, little information exists on the micro- or nano-encapsulation of CNMA in zein matrices and no data have reported on their use in multilayer system as antimicrobial agent against foodborne pathogens.

These results demonstrated, for the first time, that the controlled release achieved by the ultrathin zein/CNMA interlayer (at micro- and nanoscale) between PHBV/PHBV outer layers successfully protect the active compound from any interaction with the surrounding environment and preserved it from volatilization. Therefore, PHBV layers seemed to protect the CNMA in a greater extent and these multilayer systems can be postulated as an alternative way to produce active biodegradable and renewable food packaging materials.

Table 3 Fitting the non-linear model (Eq. 3) to experimental data of the release profile

\begin{tabular}{|c|c|c|c|c|c|c|c|c|}
\hline Sample & $\begin{array}{l}R^{2} \\
\text { adjust }\end{array}$ & RSME & $\mathrm{M}_{\infty, \mathrm{F}}$ & $K_{F}$ & $\mathrm{M}_{\infty, \mathrm{R} 1}$ & $K_{R I}$ & $\mathrm{M}_{\infty, \mathrm{R} 2}$ & $K_{R 2}$ \\
\hline PHBV + zein/CNMA & 0.987 & $2.09 \times 10^{-3}$ & $\begin{array}{l}4.12 \times 10^{-2} \\
(40.48 \%)\end{array}$ & $\begin{array}{l}0.231 \\
\quad(30.12 \%)\end{array}$ & $\begin{array}{l}8.63 \times 10^{-2} \\
(25.83 \%)\end{array}$ & $\begin{array}{l}9.02 \times 10^{-2} \\
(43.98 \%)\end{array}$ & & \\
\hline $\begin{array}{l}\text { PHBV + zein/ } \\
\text { CNMA + PHBV }\end{array}$ & 0.998 & $4.12 \times 10^{-3}$ & $\begin{array}{r}6.28 \times 10^{-3} \\
(26.09 \%)\end{array}$ & $\begin{array}{l}0.008 \\
\quad(70.12 \%)\end{array}$ & $\begin{array}{r}1.21 \times 10^{-2} \\
(37.98 \%)\end{array}$ & $\begin{array}{r}4.09 \times 10^{-2} \\
(26.98 \%)\end{array}$ & $\begin{array}{l}0.3 \times 10^{-2} \\
\quad(22.12 \%)\end{array}$ & $\begin{array}{l}6.03 \times 10^{-3} \\
\quad(43.25 \%)\end{array}$ \\
\hline $\begin{array}{l}\text { PHBV + zein/ } \\
\text { CNMA + alginate }\end{array}$ & 0.971 & $3.12 \times 10^{-3}$ & $\begin{array}{l}1.12 \times 10^{-2} \\
(34.12 \%)\end{array}$ & $\begin{array}{l}0.091 \\
\quad(24.18 \%)\end{array}$ & $\begin{array}{r}15.21 \times 10^{-2} \\
(57.75 \%)\end{array}$ & $\begin{array}{l}2.12 \times 10^{-2} \\
(12.11 \%)\end{array}$ & $\begin{array}{l}0.72 \times 10^{-2} \\
(34.15 \%)\end{array}$ & $\begin{array}{l}3.41 \times 10^{-4} \\
(78.23 \%)\end{array}$ \\
\hline
\end{tabular}

Evaluation of the quality of the regression on the basis of RMSE and $R^{2}$. Estimates' precision is evaluated using the SHW\% (in parenthesis)

$M_{\infty, F}$ equilibrium mass resulting from contribution of Fickian diffusion (unrelaxed polymer), $M_{\infty, R}$ equilibrium mass resulting from contributions of polymeric relaxation processes, $K_{R}$ relaxation rate constant, $K_{F}$ Fickian rate constant 


\section{Release Study}

Ethanol at $10 \%$ was used as food simulant, which is assigned for foods that have a hydrophilic character and are able to extract hydrophilic substances. According to the systems used, different release behaviours were observed which can be explained by the different composition of the multilayer structures. Figure $6 \mathrm{a}-\mathrm{c}$ shows the release profiles of the developed multilayer where after approximately $25 \mathrm{~h}$ (1500 min), the CNMA was released from the multilayers. Figure $6 \mathrm{~d}$ shows an example of the fitting of model-generated values to experimental data, where it is possible to observe the good fitting of the results. This good fitting is confirmed by the fitting parameters presented in Table 3. From $R^{2}$ and RSME, it is possible to confirm the good precision of regression $\left(R^{2}>0.971\right)$ and estimated (RSME) parameters of the data to the LSM fitting. These results suggest that this model can be used to describe the release transport mechanisms of CNMA from multilayer structures. The parameters obtained from the model (Table 3) show that besides Fick's, Case II transport can also explain the release of CNMA from the multilayer systems. For PHBV + zein/CNMA system, only one relaxation phenomenon was observed, being $K_{F}>K_{R l}$, where $K_{F}$ represents the Fickian diffusion rate and $K_{R l}$ the relaxation rate constant. Nevertheless, the mass released by diffusion is in the same range of the mass released due to the relaxation of the polymer. This polymer relaxation can be justified by the sensibility of zein to ethanol. For the other systems, PHBV + zein/CNMA + PHBV and PHBV + zein/CNMA + alginate one more relaxation phenomena was detected, which can be explained by the presence of one more layer in the system which covered the electrospun interlayer. In these two three-layer systems, the $K_{F}$ decreases when compared with the PHBV + zein/CNMA systems which can be explained by the fact that the zein layer is protected by the outer PHBV or alginate layers. This can also justify the decrease of CNMA released by diffusion. The first relaxation phenomenon occurred in all the multilayer systems and is responsible by the highest amount of CNMA released from all the systems $\left(\mathrm{M}_{\infty, \mathrm{R} 1}>\mathrm{M}_{\infty, \mathrm{F}}\right.$ and $\mathrm{M}_{\infty, \mathrm{R} 2}$ ). Results showed that, according to the composition of the multilayer structures, the amount of CNMA released changed, being the PHBV + zein/CNMA + PHBV multilayer system the one that releases the lower amount of CNMA. These results could explain the antimicrobial results, which indicate that this multilayer system is the one that shows the higher retaining capacity of CNMA during processing and storage; i.e. PHBV + zein/CNMA + PHBV multilayer films present the higher activity after 30 days of storage which can be related with a lower loss of CNMA during this period, behaviour that is in agreement with the lowest release of CNMA in the food simulant.

\section{Conclusions}

Bio-based films are good vehicles for the incorporation of active compounds in order to improve stability, efficiency and release of those molecules. Meanwhile, the incorporation of active compounds in multilayer systems has not been explored, and if considering the use of bio-based polymers for the development of the systems, very few studies are presented. This work shows that zein ultrathin fibres with and without cinnamaldehyde (CNMA) can be electrospun onto one side of PHBV8 films and act as a base for the development of multilayer systems. The incorporation of active agents into the multilayer structures, besides adding new functionalities, can also cause changes in the structure and physicochemical properties of films that will influence the release behaviour of the active compound.

These results showed, for the first time, that the controlled release achieved by structuring zein/CNMA interlayer between PHBV/PHBV outer layers protect the active compound from any interaction with the surrounding environment and preserved it from burst release (e.g. volatilization). Therefore, PHBV outer layers seemed to protect the CNMA in a greater extent and these multilayer systems can be postulated as an alternative way to produce active biodegradable and renewable food packaging materials which could improve the shelflife of a packaged product (e.g. high perishable foods affected by microbial contamination).

This work presents a new concept of biodegradable active multilayer systems that may help in the controlled release of active compounds and can be a guide for the development of new materials.

Acknowledgments Miguel A. Cerqueira (SFRH/BPD/72753/2010) and Ana I. Bourbon (SFRH/BD/73178/2010) are recipient of a fellowship from the Fundação para a Ciência e Tecnologia (FCT, POPH-QREN and FSE Portugal). J.L. Castro-Mayorga is supported by the Administrative Department of Science, Technology and Innovation (Colciencias) of Colombian Government. M. J. Fabra is a recipient of a Ramon y Cajal contract (RyC-2014-158) from the Spanish Ministry of Economy and Competitiveness. This study was supported by the Portuguese Foundation for Science and Technology (FCT) under the scope of the strategic funding of UID/BIO/04469/2013 unit and COMPETE 2020 (POCI-01-0145-FEDER-006684) and of the Project RECI/BBB-EBI/ 0179/2012 (FCOMP-01-0124-FEDER-027462). The support of EU Cost Action MP1206 is gratefully acknowledged.

\section{References}

ASTM-E96-15 (2011). Standard test methods for water vapor transmission of materials. In A. S. f. T. a. Materials (Ed.), Annual Book of ASTM Standards. Philadelphia.

Balaguer, M. P., Lopez-Carballo, G., Catala, R., Gavara, R., \& Hernandez-Munoz, P. (2013). Antifungal properties of gliadin films incorporating cinnamaldehyde and application in active food packaging of bread and cheese spread foodstuffs. International Journal 
of Food Microbiology, 166(3), 369-377. doi:10.1016/j. ijfoodmicro.2013.08.012.

Berens, A. R., \& Hopfenberg, H. B. (1978). Diffusion and relaxation in glassy polymer powders: 2 . Separation of diffusion and relaxation parameters. Polymer, 19(5), 489-496. doi:10.1016/0032-3861(78 )90269-0.

Bordes, P., Hablot, E., Pollet, E., \& Averous, L. (2009). Effect of clay organomodifiers on degradation of polyhydroxyalkanoates. Polymer Degradation and Stability, 94(5), 789-796. doi:10.1016/j. polymdegradstab.2009.01.027.

Busolo, M., Torres-Giner, S., \& Lagaron, J. M. (2009). Enhancing the gas barrier properties of polylactic acid by means of electrospun ultrathin zein fibers. In ANTEC, proceedings of the 67th annual technical conference, Chicago, IL (pp. 2763-2768))

Cerqueira, M. A., Costa, M. J., Fuciños, C., Pastrana, L. M., \& Vicente, A. A. (2014). Development of active and nanotechnology-based smart edible packaging systems: physical-chemical characterization. Food and Bioprocess Technology, 7(5), 1472-1482.

Cerqueira, M. A., Souza, B. W. S., Martins, J. T., \& Vicente, A. A. (2010). Improved hydrocolloid-based edible coatings/films systems for food applications. In A. Tiwari (Ed.), Polysaccharides: development, properties and applications (pp. 299-332). New York: Nova Science Publishers.

Cerqueira, M. A., Souza, B. W. S., Teixeira, J. A., \& Vicente, A. A. (2012). Effect of glycerol and corn oil on physicochemical properties of polysaccharide films: a comparative study. Food Hydrocolloids, 27(1), 175-184. doi:10.1016/j.foodhyd.2011.07.007.

Crank, J. (1975). The mathematics of diffusion (2nd ed.). Oxford: Clarendon Press.

De Azeredo, H. M. C. (2012). Antimicrobial nanostructures in food packaging. Trends in Food Science \& Technology, in Press.

Fabra, M., López-Rubio, A., \& Lagaron, J. (2015). Three-layer films based on wheat gluten and electrospun PHA. Food and Bioprocess Technology, 8(11), 2330-2340. doi:10.1007/s11947015-1590-0.

Fabra, M. J., Busolo, M. A., Lopez-Rubio, A., \& Lagaron, J. M. (2013a). Nanostructured biolayers in food packaging. Trends in Food Science \& Technology, 31(1), 79-87. doi:10.1016/j.tifs.2013.01.004.

Fabra, M. J., Lopez-Rubio, A., \& Lagaron, J. M. (2013b). High barrier polyhydroxyalcanoate food packaging film by means of nanostructured electrospun interlayers of zein. Food Hydrocolloids, 32(1), $106-114$.

Fabra, M. J., López-Rubio, A., \& Lagaron, J. M. (2014). On the use of different hydrocolloids as electrospun adhesive interlayers to enhance the barrier properties of polyhydroxyalkanoates of interest in fully renewable food packaging concepts. Food Hydrocolloids, 39(0), 77-84. doi:10.1016/j.foodhyd.2013.12.023.

Hutchings, J. B. (1999). Food and colour appearance Gaithersburg, MD: Chapman and Hall Food Science Book, Aspen Publication.
Japanese Industrial Standard (JIS) Z 2801 (2010) (English): Antibacterial products-test for antibacterial activity and efficacy https://law. resource.org/pub/jp/ibr/jis.z.2801.e.2010.pdf

Jost, V., \& Langowski, H.-C. (2015). Effect of different plasticisers on the mechanical and barrier properties of extruded cast PHBV films. European Polymer Journal, 68, 302-312. doi:10.1016/j. eurpolymj.2015.04.012.

Kujawa, P., Schmauch, G., Viitala, T., Badia, A., \& Winnik, F. M. (2007). Construction of viscoelastic biocompatible films via the layer-bylayer assembly of hyaluronan and phosphorylcholine-modified chitosan. Biomacromolecules, 8(10), 3169-3176. doi:10.1021 /bm7006339.

Nostro, A., Scaffaro, R., D’Arrigo, M., Botta, L., Filocamo, A., Marino, A., et al. (2012). Study on carvacrol and cinnamaldehyde polymeric films: mechanical properties, release kinetics and antibacterial and antibiofilm activities. Applied Microbiology and Biotechnology, 96(4), 1029-1038. doi:10.1007/s00253-012-4091-3.

Pinheiro, A. C., Bourbon, A. I., Vicente, A. A., \& Quintas, M. A. C. (2013). Transport mechanism of macromolecules on hydrophilic bio-polymeric matrices - diffusion of protein-based compounds from chitosan films. Journal of Food Engineering, 116(3), 633638. doi:10.1016/j.jfoodeng.2012.12.038.

Plackett, D., \& Siro, I. (2011). Polyhydroxyalkanoates (PHAs) for food packaging. In J. M. Lagaron (Ed.), Multifunctional and nanoreinforced polymers for food packaging (pp. 498-526). Cambridge: Woodhead Publishing Limited.

Regulation, C. (2011). on plastic materials and articles intended to come into contact with food. In E. Comission (Ed.), $N^{\circ}$ 10/2011: Official Journal of the European Union.

Scandola, M., Focarete, M. L., Adamus, G., Sikorska, W., Baranowska, I., Świerczek, S., et al. (1997). Polymer blends of natural poly(3hydroxybutyrate-co-3-hydroxyvalerate) and a synthetic atactic poly(3-hydroxybutyrate). Characterization and biodegradation studies. Macromolecules, 30(9), 2568-2574. doi:10.1021 /ma961431y.

Souza, M., Vaz, A. M., Silva, H., Cerqueira, M., Vicente, A., \& Carneiroda-Cunha, M. (2015). Development and characterization of an active chitosan-based film containing quercetin. Food and Bioprocess Technology, 8(11), 2183-2191. doi:10.1007/s11947-015-1580-2.

Torres-Giner, S., Martinez-Abad, A., Ocio, M. J., \& Lagaron, J. M. (2010). Stabilization of a nutraceutical omega-3 fatty acid by encapsulation in ultrathin electrosprayed zein prolamine. Journal of Food Science, 75(6), N69-N79. doi:10.1111/j.1750-3841.2010.01678.x.

Tran, P. A., Hocking, D. M., \& O'Connor, A. J. (2015). In situ formation of antimicrobial silver nanoparticles and the impregnation of hydrophobic polycaprolactone matrix for antimicrobial medical device applications. Materials Science and Engineering: C, 47, 63-69. doi:10.1016/j.msec.2014.11.016. 